\title{
ENTRAVES NA APRENDIZAGEM DE JOVENS E ADULTOS
}

\author{
Elizete Santiago dos Santos ${ }^{1}$ \\ Rosana Rego de Almeida²
}

\section{Resumo}

Este artigo tem como objetivo refletir acerca dos entraves na aprendizagem de jovens e adultos. Os alunos da Educação de Jovens e Adultos (EJA) apresentam algumas barreiras no ensino, e eles alunos consideram a escola como um espaço de socialização e de construção de conhecimentos. O sistema escolar ainda está se adequando a modalidade de ensino EJA, pois os indivíduos da EJA se preocupam em os conteúdos estarem de acordo com suas necessidades do dia a dia, sendo assim se faz necessário tornar a aprendizagem significativa para todos. A metodologia utilizada foi a pesquisa bibliográfica em livros, revistas, artigos da internet. Conclui-se que existem problemas de caráter interno e externo que contribuem para as dificuldades de aprendizagem da clientela da EJA com por exemplo pouca afinidade com as disciplinas de português e matemática; dificuldade de concentração o cansaço, entre outros.

Palavras Chaves: Educação de Jovens e Adultos. Dificuldades. Entraves. Aprendizagem

\begin{abstract}
This article aims to reflect on the obstacles in the learning of young people and adults. Students of Youth and Adult Education (EJA) present some barriers in teaching, and they consider the school as a space for socialization and knowledge construction. The school system is still adapting to the EJA teaching modality, since EJA individuals are concerned with the content being in accordance with their daily needs, so it is necessary to make learning meaningful for everyone. The methodology used was bibliographic research in books, magazines, articles on the internet. It is concluded that there are internal and external problems that contribute to the learning difficulties of the EJA clientele with, for example, little affinity with the subjects of Portuguese and mathematics; difficulty concentrating, tiredness, among others.
\end{abstract}

Keywords: Youth and Adult Education. Difficulties. Barriers. Learning

\section{Introdução}

As expectativas dos alunos da Educação de Jovens e Adultos (EJA) que já estão com idade avançada para o ensino regular é o de poder conseguir se alfabetizar ou aprimorar o conhecimento que já tem, a fim de competir com igualdade de condições no mercado de trabalho e na sociedade onde vive. Mas quando voltam à escola encontram na EJA, geralmente, práticas parecidas com as utilizadas nas turmas onde há alunos na idade/série adequadas, pois:

Não importando a idade dos alunos, a organização dos conteúdos a serem trabalhados e os modos privilegiados de abordagem dos mesmos seguem as

\footnotetext{
1 Mestra em Ciências da Educação pela Faculdade Interamericana de Ciências Sociais - FICS; Especialista em Docência do Ensino Superior pela Dom Pedro ;Especialista em Gestão Escolar pela Castelo Branco; Graduada em Historia pela FACIBA; Graduada em Pedagogia pela UNEB; Bacharel em Filosofia e Teologia pelo IUCH. Email: eli.zetesantiago@hotmail.

2 Mestra em Ciências da Educação pela Faculdade Interamericana de Ciências Sociais - FICS; Pós graduada em Psicopedagogia, Pós graduada em Educação Infantil pela CESAP; Licenciada em Pedagogia pela UNIFACS; Docente no Colégio Costa Pinto em Dias D'Ávila. Email: rosanafpedagogia@gmail.com
} 
propostas desenvolvidas para as crianças do ensino regular. Os problemas com a linguagem utilizada pelo professorado e com a infantilização de pessoas que, se não puderam ir à escola, tiveram e têm uma vida rica em aprendizagens que mereceriam maior atenção, são muitos (OLIVEIRA, 2007, p. 88).

No que diz respeito às séries iniciais do ensino fundamental essa infantilização dos conteúdos se faz mais presente, o que torna ainda mais difícil a aprendizagem, pois um aluno adulto não se adequa, não é estimulado com a mesma metodologia utilizada com crianças de seis a dez anos, uma vez que:

A educação oferecida a esses sujeitos está referenciada no currículo elaborado para crianças e adolescentes, o que contraria a sua especificidade estabelecida nas leis que regem a Educação de Jovens e Adultos (SOGLIA; SANTOS, 2010, p. 5).

O educador deve trazer para a sala de aula da Educação de Jovens e Adultos (EJA) a realidade vivenciada por estes educandos, ou seja, utilizar-se do que é real no seu dia-a-dia, trabalhar com palavras que ele utiliza como materiais que ele usa em seu trabalho, listas de materiais de construção, receitas, textos relacionados a temas atuais, entre outros (FREIRE, 1981).

$O$ aluno da EJA tem maior dificuldade na aprendizagem, e para que essa dificuldade seja sanada deve-se escolher um método de ensino no qual esse aluno se sinta estimulado e valorizado naquilo que já sabe, pois ninguém é um livro em branco onde $\mathrm{o}$ educador preenche as páginas com o que acha que seja o melhor. $O$ educando, tanto a criança, quanto o jovem e adulto já traz o seu saber, de suas vivencias, de seu convívio em sociedade, de tudo que aprendeu formalmente ou informalmente. Cabe ao professor utilizar este saber para transformá-lo em um saber elaborado, agregando novos conhecimentos, os conhecimentos chamados de educação formal.

\section{O Aluno da Educação de Jovens e Adultos (EJA)}

Os sujeitos dessa modalidade trazem na bagagem experiências adquiridas dentro e fora da escola, apesar de seu mérito na sociedade a escola não é o único lugar onde se obtém o saber, assim faz com que o compartilhamento de experiências entre aluno e professor seja mais livre e o aprendizado torne-se reciproco. Essas histórias muitas vezes deixam marcas profundas e podem repercutir na caminhada de vida desse educando, e faz com que o mesmo se desvalorize passando despercebida a sua capacidade de conhecer e se transformar. 
O aluno adulto deseja um aprendizado voltado para seus interesses, ele precisa estar bem, conhecer e acreditar em si mesmo, na sua capacidade intelectual, para ter autoconfiança e otimismo precisa ser elogiado. Para que possa exercitar o raciocínio lógico e a reflexão precisa ser estimulado, ver um sentido na aprendizagem quando alguém o valoriza dando ênfase aos conhecimentos adquiridos ao longo de sua vida utilizando-os para alcançar novos conhecimentos que sejam úteis e façam com que ele conquiste seus objetivos, pois:

Respeitando os sonhos, as frustações, as dúvidas, os medos, os desejos dos educandos, crianças, jovens ou adultos, os educadores e educadoras populares têm neles um ponto de partida para a sua ação. Insista-se, um ponto de partida e não de chegada (FREIRE, 1993, p. 16).

Como principal característica da Educação de Jovens e Adultos (EJA) o sujeito como ator do seu próprio aprendizado, a educação para conscientizar o aluno, formar sujeitos críticos e a liberdade de expressão. Dessa forma o aluno precisa da escola para atingir seus objetivos e satisfazer seus anseios. Pode-se explica nesse sentido que:

Muitas vezes a escola se apresenta aos alunos como um pesado elefante. A primeira impressão deixada para o estudante é de alguma coisa impossível de ser ultrapassada. Poucos terão a alegria e certeza de poder enfrentar esse peso, mais próximo do desgosto do que felicidade (WERNECK, 1999, p.23)

As crianças assimilam com naturalidade, em seu tempo, as informações, as processam de forma que lhe é peculiar, essa realidade é diferente para o educando jovem ou adulto. A maioria dos alunos da Educação de Jovens e Adultos (EJA) possui baixo desenvolvimento cognitivo, e as causas podem ser neurológicas, ou por outros fatores como exemplo, cultura, sociedade, ambiente, ou seja:

Os problemas de aprendizagem não são restringíveis nem a causas físicas ou psicológicas, nem a análises das conjunturas sociais. É preciso compreendê-los a partir de um enfoque multimensal, que amalgame fatores orgânicos, cognitivos, afetivos, sociais e pedagógicos, percebidos dentro das articulações sociais. Tanto quanto a análise, as ações sobre os problemas de aprendizagem devem inserir-se num movimento mais amplo de luta pela transformação da sociedade (SCOZ, 1994, p. 22).

Esses jovens e adultos em sua maioria com baixa autoestima se sentem oprimidos através da educação formal, vivem em condições precárias no que diz respeito a saúde, moradia, trabalho, alimentação. $O$ educador em sala de aula não está diante apenas de pessoas que querem aprender, mas sim de cidadãos que sobrevivem em momentos e situações de dificuldades, desânimos e ainda assim buscam melhoria na qualidade de vida. Pode-se afirmar que: 
Um programa de educação de adultos, por essa razão, não pode ser avaliado apenas pelo seu rigor metodológico, mas pelo impacto gerado na qualidade de vida da população atingida. A educação de adultos está condicionada às possibilidades de uma transformação real das condições de vida do alunotrabalhador. Os programas de educação de jovens e adultos estarão a meio caminho do fracasso se não levarem em conta essas premissas, sobretudo na formação do educador (GADOTTI, 2008, p.32).

O trabalho do professor na EJA é complexo e desafiador, pois envolve questões diversas no que diz respeito à educação, sabe-se que tende a ser distinta da educação para as crianças e adolescentes em ensino regular. Muitas vezes o educador encontra-se despreparado para essa nova realidade, precisará se aprimorar através do estudo, da teoria e prática, buscando se ajudar e assim ajudará na aprendizagem dos alunos. Complementa-se que:

No mínimo, esses educadores precisam respeitar as condições culturais do jovem e do adulto analfabeto. Eles precisam fazer o diagnóstico históricoeconômico do grupo ou comunidade onde irão trabalhar e estabelecer um canal de comunicação entre o saber técnico (erudito) e o saber popular (Ibid., p. 17)

A amizade entre o educando e o educador é importante no processo de aprendizagem, pois a exata relação docente só é possível na amizade a partir do momento que o docente preservando seu próprio lugar, do fundo do seu ser, se põe também ao lado do discente.

Os conflitos diários fazem com que os educandos se sintam desestimulados podendo levá-los a perder o interesse pelos estudos, a amizade, a confiança, um contato gentil, caloroso com o professor pode ajudar a despertar a vontade de aprender e assimilar os conteúdos propostos no processo de ensino aprendizagem.

A inimizade entre ambos pode atrapalhar o processo de alfabetização, afetando a permanência na escola ocasionando assim a frustração dos sonhos de luta pela liberdade e melhorar a condição de vida. O aluno ainda é marginalizado e discriminado pela sua sociedade fazendo-o se sentir incapaz de aprender, todos envolvidos nesse processo devem incentivar o sujeito da Educação de Jovens e Adultos (EJA).

São diversas as possíveis causas da dificuldade de aprendizagem dos sujeitos da EJA, forma-se um leque de possibilidades que envolvem o aluno, os pais, os filhos e familiares, a escola enquanto estrutura e os professores. O ensino e a aprendizagem andam lado a lado, ocorrem de forma simultânea e toda e qualquer dificuldade se torna um impedimento para a concretização do aprender. 


\section{Dificuldades na Aprendizagem de Jovens e Adultos}

O modelo de ensino EJA possui suas particularidades e seus sujeitos são cercados de experiências e aprendizados diferentes um dos outros. Esses discentes não podem ser apenas considerados diferentes, mas pessoas com pensamentos próprios e que possuem uma imensa bagagem cultural e social adquiridas na convivência comunitária e familiar.

Quando se fala em aprendizagem muitas ideias são apresentadas acerca de descobertas, entendimentos, transformação e aprendizado ligados diretamente aos alunos. A aprendizagem possibilita a troca de experiência entre aluno e professor, é importante ter em mente que o diálogo vai bem além de uma conversa. É significativo considerar que aprender é construir estratégias e desenvolver um planejamento a fim de dividi-lo com outras pessoas, e:

\footnotetext{
Aprender é considerado como uma situação complexa que se move em múltiplas direções e que envolve a todos sem distinção, na qual todos têm voz e visibilidade, visto que assim não apenas contribuem para a aprendizagem, como é a relação entre escuta e intercâmbio que possibilita a aprendizagem (HERNÁNDEZ, 2002, p. 21).
}

A aprendizagem é fundamentada na base do diálogo acreditando-se que o professor e o aluno possuem conhecimentos que podem ser compartilhados, pois "o processo de ensino e de aprendizagem implica em co-responsabilidade do professor e do aluno" (LEMOS, 2006, p. 60). O processo de aprendizagem torna necessário o compromisso do educador e também do educando sendo que esse deve saber sobre quais conceitos domina. Com relação a aprendizagem pode-se afirmar que:

\section{A instrução e o conhecimento não são o mesmo para todos, e também difere de acordo com os níveis de desenvolvimento de cada um, pois há domínios exigidos para que seja possível construir determinados conhecimentos (SALLA, 2012, p.54).}

Sabe-se que na sala da Educação de Jovens e Adultos (EJA) encontram-se turmas com alunos de variadas idades, sendo adolescentes, adultos e idosos, que possuem níveis diferentes tanto de aprendizagem quanto de raciocínio Essa diversidade de sujeitos, o fato que o período do ano letivo é menor que o do ensino regular são elementos que também interferem no processo do ensino aprendizagem nessa modalidade. Os alunos da EJA são formadores de ideias, possuidores de sentimentos e se permitem aprender como qualquer outro aluno, por esse motivo eles 
precisam de um olhar especial. No que diz respeito ao letramento pode-se afirmar que:

Não se restringe ao aprendizado automático e repetitivo dos códigos convencionais da leitura e da escrita ensinados tradicionalmente nas escolas (...) ele acontece antes e durante a alfabetização e continua para o resto da vida (SOEK, 2009, p. 40).

Muitas pessoas tem uma ideia errônea a respeito do letramento acreditando que a pessoa letrada é também alguém alfabetizado, o letramento tem uma base ampla, e acontece por meio de influências sociais, pois:

\begin{abstract}
Uma última interferência que se pode tirar do conceito de letramento é que um indivíduo pode não saber ler e escrever, isto é, ser analfabeto, mas ser, de certa forma, letrado (atribuindo a este adjetivo sentido vinculado a letramento). Assim um adulto pode ser analfabeto, porque marginalizado social e economicamente, mas, se vive em um meio em que a leitura e a escrita têm presença forte, se interessa em ouvir a leitura de jornais feita por um alfabetizado, se recebem cartas que outros leem para ele, se dita cartas para que um alfabetizado a escreva (e é significativo que, em geral, dita usando vocabulários e estrutura próprios da língua escrita), se pede a alguém que lhe leia avisos ou indicações afixados em algum lugar, esse analfabeto é, de certa forma, letrado, porque faz uso da escrita, envolve-se em práticas sociais de leitura e de escrita (SOARES, 2010, p. 24).
\end{abstract}

Todo individuo é letrado mesmo que não tenha aprendido a ler e escrever, o conhecimento obtido com a experiência deve ser reconhecido. A alfabetização não está baseada apenas em perceber e memorizar, e de acordo com o método de Freire as palavras devem ser criadas não descartando a abrangência da escrita e do código, mas que possibilite ao educando uma leitura critica. Faz-se necessário sinalizar que a metodologia tradicional não é adequada para o modelo da Educação de Jovens e Adultos (EJA) e não desperta o interesse do aluno adulto e deste modo percebe-se que:

A alfabetização não pode se fazer de cima para baixo, nem de fora para dentro, como uma doação ou uma exposição, mas de dentro para fora pelo próprio analfabeto, somente ajustado pelo educador. Esta é a razão pela qual procuramos um método que fosse capaz de fazer instrumento também do educando e não só do educador (FREIRE, 1979, p. 72).

A alfabetização e o letramento se completam, pois o primeiro só acontece quando o segundo faz parte, ou seja, um indivíduo só irá compreender um texto e ser hábil na escrita se tiver um conhecimento de mundo que o proporcione a interpretação. Esse conhecimento de mundo poderá contribuir para facilitar a compreensão da leitura e no desenvolvimento de uma boa escrita para o tema proposto, porque "ninguém 
educa ninguém, como tampouco ninguém se educa a se mesmo: os homens se educam em comunhão, mediatizados pelo mundo" (Id., 2005, p. 79).

No processo de ensino aprendizagem a leitura é de suma importância, através dela existe a possibilidade de ampliar os conhecimentos e trocar novas experiências. A busca pelo saber, o contato com culturas diferentes e pensamentos diferentes são algumas das diversas possibilidades que a leitura proporciona ao cidadão, além de aumentar a capacidade de comunicação. Sabe-se que a leitura é uma fonte inesgotável de conhecimento, mas nem todos se interessam por ela, algumas pessoas não se interessam em praticar a leitura e esse é um dos problemas encontrados nos alunos da Educação de Jovens e Adultos (EJA), pode-se acrescentar que:

A constatação de um fracasso generalizado com relação ao ensino de leitura na escola é, entretanto inegável. Por isso, é urgente para nós todos, professores de jovens e adultos, entendermos que a leitura deve significar uma possibilidade real da inserção dos nossos alunos no mundo da informação e consequente conhecimento para um efetivo exercício da cidadania, pois a possibilidade de intervenção na realidade se faz pelo domínio que a condição de leitor oferece aos sujeitos (MATTA, 2009, p. 70).

A escrita também se faz importante, pois faz parte do dia a dia das pessoas ocasionando benefícios sociais e intelectuais, e é geralmente no período da alfabetização que se pode obter a aprendizagem da escrita. $O$ ensino da escrita proporciona aos alunos a capacidade de produzir textos coerentes seguindo as características da linguagem formal, e:

Numa sociedade como a nossa, a escrita como manifestação formal dos diversos tipos de letramento, é mais do que uma tecnologia. Ela se tornou um bem social indispensável para enfrentar o dia a dia, seja nos centros urbanos ou na zona rural. Neste sentido, pode ser vista como essencial à própria sobrevivência no mundo moderno. Não por virtudes que lhe são imanentes, mas pela forma como de impôs e a violência com que penetrou nas sociedades modernas e impregnou as culturas de um modo geral. Por isso friso que ela se tornou indispensável, ou seja, sua prática e avaliação social a elevaram a um status mais alto, chegando a simbolizar educação, desenvolvimento e poder (MARCUSCHI, 2010, p. 16-17).

A escola tem a responsabilidade de orientar os discentes nas produções textuais, é importante que os professores aprimorem constantemente suas práticas de abordagem dos conteúdos para permitir a aprendizagem com mais facilidade e clareza. Os docentes da EJA precisam analisar que esses alunos já possuem o conhecimento da escrita mesmo que eles ainda não sejam alfabetizados, por que:

Os alfabetizandos jovens e adultos, por mais que não tenham frequentado a escola regular, convivem no meio social com diferentes tipos de escritas, tais como documentos, propagandas, rótulos, etc. Além disso, ao iniciar o 
processo de alfabetização já trazem consigo diferentes hipóteses sobre o mundo letrado, função da leitura e da escrita, assim como toda uma experiência com a oralidade (SOEK, HARACEMIV E STOLTZ, 2009 p. 41).

O educador ao trabalhar a escrita deve levar em consideração os diversos aspectos que envolvem a contribuição do educando para a construção de um texto. Ao aplicar uma construção de texto em sala de aula deve-se analisar o conhecimento dos alunos acerca do gênero e do assunto que será abordado, porque muitas vezes esses alunos não praticam constantemente a escrita em seu dia a dia, pois:

\begin{abstract}
Não basta saber escrever para escrever. É preciso ter uma motivação para isso. Grande parte da população das cidades trabalha em serviços que não exigem a escrita. Por isso, os programas de alfabetização - sobretudo de adultos - precisam ser elaborados não em função de uma cultura julgada ideal e excelente para todos, mas de acordo com as reais necessidades e anseios de cada um. A arte literária não é motivação para escrita para todas as pessoas, pelo contrário, penso que é de fato para poucas (CAGLIARI, 2009, p. 88).
\end{abstract}

Procurar saber o que os alunos anseiam da escrita é fundamental para despertar o interesse pela produção de textos, perguntar a eles o que pensam sobre o assunto proporciona aos mesmos a participação nas atividades desenvolvidas. Essa prática pode contribuir para que os alunos sintam prazer na escrita, necessidade de escrever, e incentivar a alcançar a plena participação dos discentes no processo de aprendizagem.

\title{
Considerações Finais
}

A educação passou por mudanças, e as novas práticas pedagógicas estão baseadas na valorização do senso critico e na autonomia de seus alunos. Essa nova visão do aprender não está associada aos métodos conservadores, mas sim na busca do aperfeiçoamento da aprendizagem com base no cotidiano, na necessidade profissional e na vivencia. Pode-se perceber que nunca houve a intenção por parte do Estado em formar cidadãos críticos, o currículo da Educação de Jovens e Adultos (EJA) ainda está embasado no ensino infantil, contrariando a proposta do ensino de jovens e adultos, pois buscam caminhos diferentes.

A educação do EJA deve proporcionar aos indivíduos a formação de um senso critico para torna-los atuantes na sociedade, os capacitando para serem formadores de opinião e que possam assim dialogar sobre conteúdos atuais, relevantes e interessantes. É a ausência desse método inviabiliza a disponibilização de uma educação de qualidade. Existe também a dificuldade relacionada à contradição entre aprendizagem e a permanência na escola, onde a exigência é que o aluno saiba ler e 
escrever, mas, infelizmente não são oferecidos condições e métodos adequados, e há a cobrança que o cidadão tenha acesso a educação desde cedo para que possam competir no mercado de trabalho.

Para atingir o objetivo de ampliar o conhecimento dos sujeitos da EJA a escola não deve focar na memorização de conteúdos, mas valorizar a interpretação, o senso crítico, pois esses sujeitos buscam a realização pessoal na conclusão dos estudos. A educação precisa de métodos inovadores que tenham o objetivo de compreender as dificuldades dos alunos, as dificuldades na aprendizagem da EJA precisam ser levadas em consideração para que não percam o interesse e não ocorra fracasso escolar.

\section{Referências:}

CAGLIARI, L. C. Alfabetização e linguística. São Paulo: Scipione, 2009.

FREIRE, P. Educação e mudança. Tradução de Moacir Gadotti e Lilian Lopes Martin. Rio de Janeiro: Paz e Terra, 1979.

FREIRE, P. Política e educação: ensaios. São Paulo, Cortez, 2003

GADOTTI, M.; ROMÃO, J. E. Educação de Jovens e Adultos: Teoria, Prática e Proposta. 10. ed. São Paulo: Cortez: Instituto Paulo Freire,2008.

HERNÁNDEZ, F. O diálogo como mediador da aprendizagem e da construção do sujeito na sala de aula. Revista: Pedagógica Pátio. Ano VI, n 22, jul/ago, 2002.

MARCUSCHI, L. A.Da fala para a escrita: atividade de retextualização. 10 ed. São Paulo: Cortez, 2010.

MATTA, R.S. Português - Linguagem e Interação. Curitiba: Bolsa Nacional do Ltda. 2009.

OLIVEIRA, I. B. Reflexões acerca da organização curricular e das práticas pedagógicas na EJA. Curitiba: Educar. Editora UFPR, 2007.

SALLA, F. Toda a atenção para a Neurociência.253.ed. São Paulo:Revista Nova Escola, 2012.

SCOZ, B. Psicopedagogia e realidade escolar, o problema escolar e de aprendizagem. Petrópolis: Vozes, 1994.

SOARES, M. Letramento:um tema em três gêneros. 4. ed.Belo Horizonte: Autentica, 2010.

SOEK, A. M.; HARACEMIV, S. M. C.; STOLTZ, T. Mediação pedagógica na alfabetização de jovens e adultos.Curitiba: Positivo, 2009. 
SOGLIA, I. S.; SANTOS, C. S. P. Educação de Jovens e Adultos: expectativas e dificuldades. 2010.2 Disponível em: em: $<$ http://www.uesb.br/eventos/semanapedagogia/anais/60CO.pdf>. Acesso em: 22 jan. de 2020.

WERNECK, H. Se a boa escola é a que reprova, o bom hospital é o que mata. 4. ed. Rio de Janeiro: DP\&A, 1999. 